\title{
Guía de práctica clínica Manejo de la Infección genital por chlamydia trachomatis
}

\section{Introducción}

En 1984 la fuerza de tareas canadiense publicó el rastreo de infección genital por chlamydia trachomatis (CT) como una recomendación de grado $D$ * en el examen periódico de salud. Es decir, la práctica estaba basada en pobre evidencia para recomendar su rastreo en población general. Al mismo tiempo, la recomendación para el grupo de mayor riesgo era de grado $\mathrm{C}$ y la recomendación durante el embarazo de grado $\mathrm{B}$.

En 1985 el CDC publicó una guía para la prevención y el control de la infección por chlamydia trachomatis, resaltando la importancia en conocer su prevalencia y remarcó la morbilidad de esta entidad.

Actualmente, la fuerza de tareas canadiense recomienda su rastreo solo en población de riesgo y durante el embarazo como recomendación grado B; mientras que para la población general es una recomndeción grado $\mathrm{D}$. La última actualización publicada de la fuerza de tareas americana (US Preventive Task Force) en cam bio, recomienda el rastreo de rutina a todas las mujeres sexualmente activas menores de 25 años y aquellas con riesgo de infección como de grado A.También recomienda el rastreo de rutina a todas las embarazadas menores de 26 años y todas las embarazadas con riesgo de infección aumentado como de grado B; y para aquellas mujeres asintomáticas o embarazadas de bajo riesgo como una recomendación grado $\mathrm{C}$. Finalmente, considera como insuficiente la evidencia para el rastreo en hombres (Recomendación I).

En la actualidad la infección por CT es una de las infecciones más frecuentes en los adultos jóvenes y entre la población de adolescentes; el curso de esta entidad es insidioso, con un gran número de infectados asintomáticos que sostienen su transmisión en la comunidad. Hasta hace poco tiempo la mayor limitación se encontraba en el test disponible para realizar el rastreo o el diagnóstico pero esta barrera ha sido superada por las técnicas de amplificación del ácido nucleico. Por otro lado, para lograr un adecuado control de esta entidad es necesario no sólo establecer programas de rastreo, sino también implementar estrategias de educación, facilitar el acceso de los pacientes;y reunir los esfuerzos sanitarios para reducir tanto su morbilidad como sus costos.

\section{Epidemiología}

La infección por CT es muy frecuente entre adolescentes sexualmente activas y adultos jóvenes. En USA es dos o cinco veces más frecuente que la infección por Neisseria Gonorrhea, en Canadá tiene una incidencia de 216 por 100000 habitantes. La infección asintomática es la más común en ambos sexos, entre el 60 y el $80 \%$ de las mujeres son asintomáticas aunque también se puede presentar como: cervicitis mucopurulenta, endometritis, salpingitis, sindrome uretral, proctitis, sepsis post aborto y perihepatitis. En estudios observacionales se la ha asociado con complicaciones a largo plazo de la enfemedad inflamatoria pelviana (EPI), infertilidad y embarazo ectópico (EE).Estudios serológicos sugieren que el $64 \%$ o más de los casos de infertilidad tubaria y el $42 \%$ de los EE se atribuirían a la infección no identificada por chlamydia trachomatis.

El rastreo en diferentes poblaciones de Canadá demuestran estado de portador entre el $1 \%$ y $25 \%$, siendo mayor porcentaje en el grupo de 15 a 19 años y luego en el de 20 a 25 años de edad. Otros factores asociados con riesgo aumentado de infección son: tener más de dos parejas por año, pertenecer a un bajo nivel socioeconómico, no uso de preservativos o uso incorrecto del mismo, sangrado inter menstrual, friabilidad de cervix, y secreción mu- copurulenta de endocervix. La tasa de infección en embarazadas se encuentra entre el 5 y $25 \%$. En estudios prospectivos, del 11 al $44 \%$ de los recién nacidos de madres infectadas tienen conjuntivitis y entre el $11 \%$ al $20 \%$ desarrollaron neumonía durante el primer año de vida.

En los hombres la infección por chlamydia puede causar uretritis, epidididimitis, prostatitis y ocasionalmente proctitis o proctocolitis en la trasmisión homosexual. Cerca del $50 \%$ de las uretritis no gonococcicas y el $31 \%$ de las epididimitis agudas son debidas a la infección por chlamydia trachomatis y entre el 1 y el $21 \%$ de los hombres podrían ser portadores asintomáticos y funcionar como reservorio.

\section{Importancia}

La importancia del rastreo de esta entidad radica en que la infeccion asintomática por chlamydia trachomatis es la forma más frecuente de presentación, tiene secuelas importantes y representa un alto costo en salud ( los costos directos e indirectos exceden los US $\$ 2,4$ billones anuales en USA). Los test disponibles actualmente para realizar el rastreo son confiables y la entidad tiene tratamiento efectivo.Su detección temprana mejora los outcomes de salud en la población. La proporción de mujeres entre 15 y 25 años rastreadas anualmente para chlamydia trachomatis constituye hoy un indicador de las medidas HEDIS \#.

\section{Presentación clínica}

La enfermedad inflamatoria pelviana es la forma más seria de su presentación clínica aguda. La mujer se expone a esta infección por vía sexual y el sitio inicial de infección es el tracto genital bajo, aunque la uretra y el recto pueden infectarse, lo más frecuente es que se infecte el cervix. Los síntomas ocurren en muy pocos casos, y generalmente como disuria o flujo vaginal. El ascenso de la infección por endometrio y trompas de Fallopio puede causar anormalidades menstruales o dolor abdominal bajo.Las infecciones no tratadas pueden persistir varios meses, período en el que se puede desarrollar una complicación, y por supuesto continuar transmitiendo la infección a otros sujetos. La proporción de mujeres que desarrollan patología en el tracto reproductivo superior (endometritis, salpingitis, peritonitis pélvica) no se conoce.Por otro lado, tanto el diagnóstico como el tratamiento de la EPI no son satisfactorios y se estima que el $17 \%$ de las mujeres tratadas por EPI tendrán infertilidad y un porcentaje similar tendrá dolores pelvianos crónicos y alrededor de un $10 \%$ desarrollarán embarazo ectópico.

En las embarazadas infectadas con CT uno de los riesgos temidos es desarrollar EPI post parto.EI tratamiento oportuno de ellas y su pareja previene la enfermedad post parto y perinatal. Entre un $10-28 \%$ de las embarazadas que interrumpen su embarazo y están infectadas, desarrollará endometritis y/o salpingitis de manera similar ocurre endometritis en el 19 al $34 \%$ de las mujeres que llegan a parto de término.

Alrededor de dos tercios de los recién nacidos de madres infectadas, se contagiarán durante el parto, aunque reciban profilaxis oftálmica con nitrato de plata el $15-20 \%$ tendrá conjuntivitis y entre el 3-16\% tendrá neumonía. La CT es la causa más frecuente de conjuntivitis en los recién nacidos y una de las causas más comunes de neumonía durante los primeros meses de vida.

En los varones la forma más frecuente de presentación de la infección por CT es la uretritis y raramente deja secuelas. Los síntomas son similares a la gonorrea como la secreción uretral o dis- 
uria, pero generalmente mucho más leves.La uretritis por CT representa el $30-40 \%$ de las no gonocóccicas y el $50 \%$ de las internaciones por epididimitis en adolescentes o adultos jóvenes, y responden rápidamente al tratamiento antibiótico.Las infecciones rectales son más raras, generalmente asintomáticas pero podrían dar síntomas similares a proctitis o proctocolitis.

\section{Pruebas diagnosticas}

Las pruebas de laboratorio actualmente disponibles son el cultivo, la detección de antígenos y técnicas de amplificación del ADN. Existe clara evidencia que las técnicas de amplificación del ADN la reaccion en cadena de la ligasa (LCR) o la reaccion en cadena de la polimerasa (PCR) tienen una sensibilidad cercana la $100 \%$ y es superior al $60-80 \%$ que ofrece el cultivo o la detección de antígeno. Además tanto la LCR como la PCR pueden realizarse en muestras de orina, lo cual facilita la toma; y evita la toma más invasiva y complicada de la muestra cervical para el cultivo que además, también requiere de personal entrenado.La elección del test depende de la situación clínica, la prevalencia de la infección y las disponibilidades locales. En los hombres el análisis de la orina es de elección.

\section{Tratamiento}

El tratamiento de los infectados previene obviamente la infección en sus parejas.Particularmente el tratamiento de las embarazadas previene la trasmisión de CT a los recién nacidos durante el nacimiento y el tratamiento de la pareja reduce la reinfección en el caso índice.

La coinfección con CT generalmente ocurre en pacientes con infección por gonococco por lo cual se presume que el tratamiento de estos pacientes para CT parece apropiado.

Los regímenes de tratamiento recomendados son:

Azitromicina $1 \mathrm{~g}$ VO en única dosis, ó

Doxiciclina $100 \mathrm{mg}$ VO dos veces por dia durante 7 dias

Regímenes alternativos son:

Eritromicina $500 \mathrm{mg}$ cuatro veces por dia durante 7 dias, ó Ofloxacina $300 \mathrm{mg}$ dos veces por dia durante 7 dias, ó

Levofloxacina 500 VO durante 7 dias

El tratamiento con azitromicina y doxiciclina son igualmente efectivos, la elección de la monodosis de azitromicina se reserva cuando es dudosa la adherencia del paciente, o no se asegura su seguimiento, ya que el tratamiento con doxiciclina es de menor costo y ha sido usado durante mas tiempo.La eritromicina es menos efectiva y es frecuente su abandono por intolerancia digestiva.La eficacia de la ofloxacina es similar a la azitromicina y doxiciclina, pero es mas costosa y no ofrece mayor beneficio que las anteriores, finalmente la levofloxacina no ha sido evaluada en ensayos clínicos para el tratamiento de la CT.

Se deberían adoptar estrategias para maximizar la adherencia al tratamiento, como observar la primera toma o administrar la medicación en centros de salud. Para minimizar la trasmisión de la infección se debería instruir a los pacientes para realizar abstinencia sexual después de 7 dias de la monodosias o hasta haber completado los 7 dias del tratamiento; y para reducir el riesgo de reinfección también abstenerse hasta que la pareja haya completado el tratamiento.

En el embarazo están contraindicadas la doxiciclina y la ofloxacina. No obstante, el tratamiento con azitromicina es seguro y efec-
tivo.Se recomienda como re-test el cultivo luego de tres semanas de haber completado el tratamiento.

Los esquemas recomendados en el embarazo son los siguientes: Eritromicina base $500 \mathrm{mg}$ VO cuatro veces por dia durante 7 días Amoxicilina $500 \mathrm{mg}$ VO tres veces por dia durante 7 dias Regímenes alternativos son:

Eritromicina base $250 \mathrm{mg}$ cuatro veces por dia durante 14 dias Azitromicina $1 \mathrm{~g}$ VO unica dosis

(el estolato de eritromicina está contraindicado en el embarazo) A los pacientes VIH positivos y negativos se les indica igual tratamiento

\section{Seguimiento}

No es necesario retestear para chlamydia una vez completado el esquema con azitromicina o doxiciclina, a menos que persistan los síntomas o que se sospeche reinfección, igualmente se puede considerar retestear al paciente luego de tres semanas de haber completado el tratamiento con eritromicina ;pero no tiene validez realizar un cultivo antes de ese período.Los resultados falsos negativos pueden ocurrir como consecuencia de infección por pequeño número de microorganismos. Además el retest con técnicas diferentes del cultivo antes de tres semanas podrían dar resultados positivos (falsos positivos) por excreción de microorganiosmos muertos.

Se ha hallado alta prevalencia de CT en mujeres con antecedentes de infección en los meses previos. La mayoría de las infecciones post- tratamiento resultan de la reinfección, y generalmente porque sus parejas no han recibido tratamiento oportunamente. La reinfección aumenta el riesgo de EPI y otras complicaciones, en estas situaciones se sugiere restestear a la paciente luego de tres o cuatro meses, también se considera una población especial (de riesgo aumentado) a las adolescentes.

Es importante diferenciar el re-screening de la re-evaluacion del paciente para identificar fracaso en el tratamiento. El retesteo en general no se recomienda, excepto en las embarazadas o pacientes de dudosa adherencia.

\section{Manejo de las parejas}

Se recomienda educar a los pacientes para que convoquen a la evaluación médica a sus parejas para realizar test y recibir el tratamiento adecuado.

Se debe indicar abstinencia sexual hasta haber completado el tratamiento o continuarla durante 7 dias si han recibido monodosis.

\section{Estrategias de educación}

No hay estudios que hayan evaluado en que medida las intervenciones educacionales modifican patrones de conducta. Existen tres grupos diferentes hacia los cuales habría que dirigir estrategias educacionales éstos son los pacientes, el público en general y los profesionales de la salud. Algunas posibles estrategias podrían constituir:

1. Prevención primaria para los pacientes: promoviendo la educación sexual de manera integrada para prevención de ETS y embarazo no deseado. 
2.Prevenir la reinfección, el control de las ETS implica una complicada intervención para modificar la conducta. La educación a este nivel debería ser adecuada según los grupos etarios, sexo, clase social, raza, etc.

3. Para el público general, la educación acerca de la infección por CT debería ser parte de una estrategia educacional que integre la educación sexual y promueva el uso de preservativos.

\section{Cuadro: Recomendaciones para la búsqueda de infección por Chlamydia Trachomatis}

\section{Deberia evaluarse infección por chlamydia trachomatis}

A mujeres con sintomatología atribuible a la infección

(Recomendación gradoB)

Flujo vaginal

Sangrado intermestrual o spotting

- Cervix friable o colpitis

Uretritis

- Epi

- Dolor abdominal bajo

Artritis reactiva

A hombres con sintomatología compatible

(Recomendación gradoB)

Secrecion uretral

- Disuria

- Uretritis

- Epidídimo-orquitis

Artritis reactiva

\section{Como rastreo}

A todas las mujeres menores de 25 años de edad sexualmente activas (Recomendación gradoA)

A las mujeres a partir de los 25 años con mas de una pareja en el ultimo año (Recomendación gradoB)

\section{Circunstancias particulares en las que se deberia testear} CT

_ mujeres antes de finalizar el embarazo (Recomendación gradoA) _ pacientes que presentan otra ETS (Recomendación gradoB)

_ parejas de pacientes con CT (Recomendación gradoB)

madres de neonatos con conjuntivitis o neumonitis (Recomendación gradoB)

mujeres de riesgo que se colocaran un DIU u otro procedimiento de instrumentación uterina (Recomendación gradoB)

_ donantes de semen (Recomendación gradoB)

\section{Test diagnósticos}

Se recomienda utilizar técnicas de amplificación de ácidos nucleicos (PCR o LCR) (Recomendación gradoB)
4. Los profesionales de la salud deberían estar capacitados para entablar una real comunicación con sus pacientes para obtener su historia sexual y lograr un consejo o intervención adecuada y efectiva.

* Ver Glosario

\section{Tratamiento}

1.Para mujeres y hombres con infección no complicada

Azitromicina $1 \mathrm{~g}$ ó

- Doxiciclina $100 \mathrm{mg}$ dos veces por dia 7 dias ó

- Ofloxacina 200 dos veces por dia 7 dias

2.Para mujeres emabarazadas con infección no complicada

Eritromicina $500 \mathrm{mg}$ cuatrro veces por dia 7 dias ó

Amoxicilina 500mg tres veces por dia por 7 dias

3.Para infecciones genitales altas (como salpingitis)

Doxiclina $100 \mathrm{mg}$ dos veces por dia 10 dias más metronidazol $200 \mathrm{mg}$ tres veces por dia ó $400 \mathrm{mg}$ dos veces por dia durante 7 dias.

Como alternativa del metronidazol se puede usar clindamicina $450 \mathrm{mg}$ cuatro veces al dia.

Y como alternativa de la doxiciclina, ofloxacina $400 \mathrm{mg}$ dos veces en ell dia.

4.Para infecciones del tracto genital alto masculino

Se extiende el tratamiento con doxiciclina $100 \mathrm{mg}$ dos veces por dia hasta completar los 14 dias.

5. Cuando clínicamente se sospecha la infección, el tratamiento puede iniciarse sin necesidad de esperar el resultado del test para CT

\section{Notificación a la pareja}

Se debe notificar y tratar a la/s pareja/s de las cuatro semanas previas al comienzo de los síntomas

Se debe notificar y tratar a la/s pareja/s de los últimos seis meses previos en el caso de los pacientes asintomáticos

\section{Seguimiento}

Se debería reforzar la adherencia al tratamiento, solo re-testear si se duda de ella y si es necesario realizarlo se aconseja utilizar técnicas de amplificación de ADN y esperar un mínimo de tres semanas antes de repetirlo.

\section{Estrategias de educación}

Todos los pacientes con infección por CT deberian recibir información acerca de la entidad.Mas allá de que se debería educar acerca de la infección por CT como las otras ETS, integrada a otras tópicos de educación sexual y promover el uso del preservativo.

Dra. Vilda Discaciatti [ Unidad de Medicina Familiar y Preventiva. Hospital Italiano de Buenos Aires ]

\footnotetext{
Referencias

U.S.Preventive Services Task Force. Chamydial infection.Update, 2001.

Heidi Nelson MD, Mark Helfand MD.Screening for chlamydial Infection. Am J Prev Med 2001:20:95-107.

MMWR.Sexually transmitted diseases treatment guidelines 2002. Recomendations and reports, may 10, 2002, vol5 (www.cdc.gov )

Canadian Task Force on Preventive Health Care.Screening for chlamydial infection.1996

Scottish intercollegiate guidelines network. Managenment of genital chlamydia trachomatis infection. March 2000 (www.sing.ac.uk)

\# Health Plan Employer Data and Information Set
} 